\title{
The ABCs of the XYZs: Adding a Critical Dimension to Contemporary Teacher Education
}

\author{
Eric S. Mohr (Corresponding author) \\ School of Teacher Education and Leadership, Utah State University \\ 2805 Old Main Hill, Logan, UT 84322-2805, United States \\ Tel: 1-435-797-0828_E-mail: eric.mohr@usu.edu \\ Kathleen A. Mohr \\ School of Teacher Education and Leadership, Utah State University \\ 2805 Old Main Hill, Logan, UT 84322-2805, United States \\ Tel: 1-435-797-3946Ｅ-mail: kathleen.mohr@usu.edu
}

Received: June 22, 2018

doi:10.5296/jet.v5i2.13500
Accepted: July 18, 2018

Published: August 14, 2018

URL: http://dx.doi.org/10.5296/jet.v5i2.13500

\begin{abstract}
Currently, the faculty at post-secondary institutions are mostly Baby Boomer and Generation-X (Gen $\mathrm{X}$ ) faculty teaching Gen-Y and $-\mathrm{Z}$ students as undergraduates. According to numerous social commentators, these generations tend to vary in their worldviews, and the differences can challenge the teaching-learning relationship. In the following discussion, we would like to share some information from a few current resources that attempt to characterize and analyze the two most dominant generations among post-secondary students today. Then, we will pose a few ways that teacher educators might seek to update their instruction for Gen-Z students.
\end{abstract}

Keywords: Generation X, Generation Y, Generation Z, Post-secondary Students, Undergraduate Instruction, Varied Worldviews

As teacher educators, most of us find ourselves on a continuing quest to understand our contemporary students - elementary, secondary, and post-secondary preservice teachers who plan to be the next generation of teachers teaching the next generation of students. This 
quest inspires our desire to keep growing in critical teaching knowledge and the sociocultural contexts of our students. A few years back, we experienced a few episodes in which newer teacher candidates let us know early on that they wanted us to approach them somewhat differently than we had experienced in teacher preparation courses in the past. One of us announced to a class of teacher candidates: "Large class sizes lie ahead for most of you, and large classes require more careful planning and the intentional stacking of strategies to engage students." One student's reaction in the class was telling: "Professor, please don't take the shine off [preparing to be a teacher]." The other of us also experienced a similar misstep: when a student earned a B on one of her assignments, she proclaimed: "My family doesn't earn B's!" implying that the grading, rather than the product, was the real problem.

With these and other similar experiences, we realized that we needed to invest some significant effort to understand, teach, guide, and challenge contemporary students. Currently, the faculty at post-secondary institutions are mostly Baby Boomer and Generation-X (Gen $\mathrm{X}$ ) faculty teaching Gen-Y and $-\mathrm{Z}$ students as undergraduates. According to numerous social commentators, these generations tend to vary in their worldviews, and the differences can challenge the teaching-learning relationship. In the following discussion, we would like to share some information from a few current resources that attempt to characterize and analyze the two most dominant generations among post-secondary students today. Then, we will pose a few ways that teacher educators might seek to update their instruction for Gen-Y and $-Z$ students. We most certainly acknowledge that the dangers of stereotyping can inhibit a meaningful analysis of multi-generational academic relationships, so the following sources will simply serve to provide insight rather than two-dimensional labels of contemporary students.

\section{Two Recent Publications That Characterize Today's Undergraduates}

Generation iY: Our Last Chance to Save Their Future by Tim Elmore (2010) is one attempt to characterize late Millennials who have used the Internet most of their lives and place them in a sequence with the previous generations to demonstrate how they are different. Elmore-a Gen-Xer-is founder and president of Growing Leaders (www.growingleaders.com), an Atlanta-based nonprofit organization created to develop emerging leaders. The other source, Generation Z Goes to College by Corey Seemiller and Meghan Grace (2016), is a resource that identifies some key Gen-Z student characteristics. While Corey Seemiller is a Gen-Xer employed as a higher-education administrator and faculty member in the organizational leadership program at Wright State University, Meghan Grace is a Millennial engaged as the new-member orientation director for the Sigma Phi Epsilon fraternity. To gather relevant data, these researchers administered a survey to learn the styles, motivations, and perspectives of Gen-Z students to better work with the latest generation of students, often known as Digital Natives. Seemiller and Grace collected 613 completed surveys (of 1,143 surveyed), which revealed that $69 \%$ of the respondents were women, and $76 \%$ were white. Relevant to those who currently work with Digital Natives, their study primarily reflects their survey results and information synthesized from several resources to promote a more positive profile of Gen $\mathrm{Z}$. 
Before focusing on the student profiles, we should first characterize the generations most broadly represented at post-secondary institutions. Elmore (2010) uses the following labels and birth timeframes: Boomers (1946-1964), Busters (1965-1983), and Millennials (1984-2002). Alternatively, Seemiller and Grace (2016) make the following adjustments to birth timeframes for the last three generations: Busters (1965-1980), Millennials (1981-1994), and Gen Z, 1995-2010. In his book, Elmore describes Millennials-the Y-Generation-as "the most diverse and eclectic in our nation's history, as well as the most protected and observed" (p. 19). He also contends that they are overwhelmed, overconnected, overprotected, and overserved. Ouch! Elmore's book argues further that Generation iY-late Millennials who have grown up with the Internet - have "so much to offer, but they need direction-mentors who engage them in a relevant way, channel their energy, and provide them with the challenges they need" (p. 18). The table below (adapted from Elmore, 2010 with additions from Seemiller and Grace, 2016) depicts the last few generations of Americans and includes some interesting differences. For example, Millennials are characterized as optimistic about their futures and seeing life as a smorgasbord of choices. Millennials have also been described as entitled. Their real or surreal confidence and energy for living life have been challenged by recent economic downturns that have contributed to "quarter-life crises" for many who move back in with their parents around age 25.

Table 1. Comparison of Recent Generations

\begin{tabular}{|l|l|l|l|}
\hline Perspective & $\begin{array}{l}\text { Gen X- } \\
\text { Busters }\end{array}$ & $\begin{array}{l}\text { Gen Y- } \\
\text { Millennials }\end{array}$ & $\begin{array}{l}\text { Gen Z- } \\
\text { Digital Natives }\end{array}$ \\
\hline Birth Years & $1965-1980$ & $1981-1994$ & $1995-2010$ \\
\hline Life Paradigm & Relate to me & Life is a cafeteria & Make a difference \\
\hline View of Authority & Ignore them & Choose them & Work with them \\
\hline $\begin{array}{l}\text { View of Relation- } \\
\text { ships }\end{array}$ & Central, caring & $24 / 7$ & Collaboration, resolution \\
\hline Value System & Media & Shop Around & Open-minded \\
\hline View of Career & Irritant & Place to serve & Place to solve problems \\
\hline View of Technology & Enjoy it & Employ it & Live it \\
\hline View of Future & Hopeless & Optimistic & Solve it! \\
\hline
\end{tabular}

Table adapted from Elmore, 2010 with additions from Seemiller and Grace, 2016.

By way of contrast in looking at recent generations, Seemiller and Grace (2016) posit that Generation $\mathrm{Z}$ is an even more diverse generation. They are sometimes known as Digital Natives, Ebay babies, information curators, and, rather than the "me-centric" spirit attributed 
to Millennials, the Z Generation is considered more "we-centric."

\section{The Emerging Academic Tendencies of Gen $\mathrm{Z}$}

Because Gen-Z students are beginning to predominate post-secondary education, we want to spend the balance of our discussion on them. Once again, we do not mean for the following profile to stereotype Digital Natives as students and future citizens. Rather, we desire that these comments serve to help teacher educators to consider generational differences that might hinder the teaching-learning dynamic. Seemiller and Grace (2016) confirm that this is the dominant generation of students currently populating university campuses.

Seemiller and Grace's description of contemporary college-going freshmen is generally positive. Thus, it might be helpful for instructors to seek greater understanding of these students in order to maximize their learning. As evident in the comparison of Generations $Y$ and $\mathrm{Z}$ in Table 2 below, Gen-Z students report seeking an education that prepares them for a meaningful career. They apparently are interested in lifestyle-change challenges and appreciate standards and accreditation checklists. These attributes could contribute to a willingness to learn and develop themselves - in contrast to students who believe that they "are good to go" and view college as a way to simply defer adulthood. These Digital Native students may be more open to learning from authority figures than the previous generation. However, like their predecessors, Digital Natives may be unknowingly conflicted. While wanting to show compassion, Gen-Z students admit to being critical of their peers. Further, they identify as entrepreneurial but do not see themselves as creative. They also report being excited, yet fearful, about the future. Of particular interest to university faculty, Gen-Z students show less preference for working with others, while suffering from Fear of Missing Out (FOMO) anxiety. Such paradoxical insights should probably foster a review of how instructors use class time and assign collaborative projects with their incoming freshmen.

Table 2. Descriptive Comparison of Generations $\mathrm{Y}$ and Z

\begin{tabular}{|l|l|l|l|}
\hline iYs/Millennials & & Generation Z & \\
\hline Me Generation & Self-interested & Responsible & Not spontaneous \\
\hline High expectations & Entitled & Open-minded & Not conservative \\
\hline Optimistic & Over-confident & Thoughtful & Not focused \\
\hline Educated & Connected & Loyal & Not competitive \\
\hline Introspective & Ambiguous & Entrepreneurial & Not creative \\
\hline Parent-Supported & Trophied & Compassionate & Critical of peers \\
\hline Tolerant & Unstructured & Interactive & FOMO \\
\hline
\end{tabular}

A comparison of reported Gen-Y and Gen-Z characteristics. 


\section{Gen Z, the Next Generation of Preservice Teachers}

For the balance of this discussion, therefore, we present two likely objectives for teacher educators: to consider possible adjustments to key course assignments for preservice teachers and to encourage discourse that can communicate to teacher candidates a more productive perspective of their own coursework, as well as practices that will matter in their future classrooms.

\section{Adjusting course work and assignments for Gen-Z teacher candidates}

Gen-Z students appear to want an education that develops them as individuals and prepares them for successful and meaningful careers. We view teaching as an important profession that needs caring and enthusiastic converts. It would be wonderful if teaching would attract some of the brightest among the current generation who are committed and equipped to make a real difference in the lives of their own students. What are some of the skills that they will likely need? How can we ensure that Gen-Z teacher candidates develop them?

We teacher educators know that today's teachers need to collaborate with colleagues and model teamwork for their students. As Seemiller and Grace (2016) note, however, Gen Zs may be less interested in cooperative learning and prefer to work as individuals. Digital Natives report that they prefer flipped courses and videos posted on YouTube - both of which allow for more individual participation. Indeed, Gen $\mathrm{Z}$ students report YouTube as their go-to, number-one source of information. Both of these inclinations may create an insulating effect that tends to undercut remaining connected to other teaching colleagues in meaningful ways.

\section{One example of modifying assignments for today's preservice teachers}

Let us consider one example of possible adjustment to make a course assignment more relevant for Digital Native teacher candidates. Based on Mueller and Oppenheimer's (2014) work on the strengths of generative notetaking (summarizing learning in one's own handwriting), we could argue that all content-area teachers should find ways to reduce the unnecessary distractions of technology - that they must acknowledge technology for its own sake is no panacea for learning. Moreover, due to the textual nature of state end-of-course reading and writing assessments, secondary students must make the necessary transition from an over-reliance on video to the skills required to interpret text for reliable information. Rather obviously, today's secondary students carry one of these technology distractions that they must learn to manage every day: their smartphones.

One illustration of locating a relevant teaching context for technology employed by Digital Native preservice teachers seemed to find fertile ground. The following essential question for the first unit in a content-area literacy course required of all secondary teacher candidates seemed the right place to begin: "How can we secondary teachers help our Digital Native students make the necessary transition from video to text for reliable information?" After participating in a brief discussion of the question and reviewing an example of a state end-of-course writing assessment with a synthesis prompt, these candidates readily acknowledged the exclusive presence of text in the form of several short readings and a 
prompt that asked for argumentation. They also saw that there was no video nor any requirement to engage a smartphone.

Subsequently, using a suggestion from José Bowen (2012) in Teaching Naked, these candidates explored the idea of pre-selecting a YouTube video for their students, to which they matched an engaging frontloading/pre-reading strategy like an Anticipation Guide (Classroom Strategies for Interactive Learning; Buehl, 2014). Ultimately, these Gen-Z preservice teachers experimented with the idea that their students would still use video, but now the video material, as homework viewed perhaps on a smartphone but converted to text in a strategy-supported organizer, could appropriately frontload the comprehension of an informational text that their secondary students might explore the next class meeting.

\section{An example of a "destiny assignment"}

Other insights that we teacher educators should keep in mind in our course planning include that many post-secondary Digital Natives claim little interest in current events, perhaps because they have been bombarded by all manner of "news" their entire lives and sorting out what matters is a huge challenge for everyone. These students seem to prefer assignments that challenge them to construct their future selves as capable, caring individuals. Adjustments to Gen-Z course assignments should allow for choices (an individual sense of freedom) and on future application. We teacher educators can frame many course tasks as destiny assignments, that is, how they will need to approach their own teaching tasks.

One example of this assignment type was used in a methods course focusing on the needs of English learners. The teacher candidates were challenged to prepare their choice of brochure, flyer, or poster that would summarize research-recommended ways to connect with and elicit parental involvement in support of their children's schooling. They utilized their comfort with technology to present several concrete ways of engaging parents. In other words, the preservice teachers had the opportunity to envision themselves as classroom teachers who had a plan for parental involvement, hopefully given them a sense of their future success in a critical element of effective schooling.

\section{"Talking the walk": Encouraging a positive discourse for teacher preparation}

While adjusting our approach to assignments for the growth of preservice teachers appears paramount, teacher educators must also consider including Digital Natives in a discourse that communicates a productive perspective toward coursework that matters in their preparation as teachers. Promoting our assignments could include a preview that we offer to set students up for successful assignments - to invest students in our carefully designed tasks, which would involve a spirit of great assignments deserve great explanations, introductions, and promotions. Seemiller and Grace (2016) suggest that the way we frame the relevance of these assignments might be more relevant than ever. We call this approach "Talking the Walk." Our language as teacher educators should be laced with comments that depict potential and future success. For example: 
"You'll need this on the job."

"We're here to equip you to make a real difference."

"I want to help you be the best you can be."

"I know that you probably don't want to let others down, so you should use the techniques that we just practiced."

Overall, our frequent personalized statements of encouragement should convey a spirit of, "Professionals in this field need to know and apply these essential concepts." This notion often correlates well to stated objectives for the course or those used in student evaluation measures.

\section{Our Conclusion: An Adjusted Vision of Contemporary Teacher Preparation}

As we noted at the beginning, recent experiences helped us authors understand that we needed to invest some significant effort to understand, teach, guide, and challenge contemporary teacher candidates. With multiple generations represented at our post-secondary institutions, the faculty at post-secondary institutions are mostly Baby Boomer and Gen-X faculty preparing Gen-Y and $-Z$ students as undergraduates. Because these generations tend to vary in their views of the world, these differences can definitely challenge the teaching-learning relationship. While sharing a few sources that characterize and analyze the two most dominant generations among post-secondary students today, we sought insight into what teacher-preparation may not adequately address for our most contemporary students.

We end, therefore, with the confirmation that teacher educators might seek to update their instruction, especially for Digital Native teacher candidates. To summarize, we propose that teacher educators consider possible adjustments to key course assignments for today's preservice teachers. We also encourage an updated discourse that can communicate to teacher candidates a more productive perspective of their own coursework, as well as practices that will matter in their future classrooms. In a recent presentation, "Engaging Generation Z Students," Vickie Cook (2016) confirms that Gen-Z post-secondary students tend to desire frequent educational opportunities that use technology and visual media. She adds that they also often desire relevant, solution-oriented relationships with their mentors and peers but need guidance while they contribute to the answers that contemporary challenges demand. Indeed, we teacher educators should be some of those mentors who help shape the contributions of our Digital Native teacher candidates. The evidence continues to mount, therefore, that we must keep adjusting our instruction as our contemporary students bring their updated experiences and worldviews to our universities.

\section{References}

Bowen, J. (2012). Teaching Naked: How moving technology out of your college classroom will improve student learning. San Francisco, CA: Jossey-Bass.

Buehl, D. (2014). Classroom Strategies for Interactive Learning ( $4^{\text {th }}$ ed.). Newark, DE: International Reading Association.

Cook, V. (2016). Engaging Generation Z Students. Center for Online Learning Research 
and Service, University of Illinois Springfield. Retrieved from

https://sites.google.com/a/uis.edu/colrs_cook/home/engaging-generation-z-students.

Elmore, T. (2010). Generation iY: Our last chance to save their future. Atlanta, GA: Poet Gardener.

Mueller, P., \& Oppenheimer, D. (2014). The Pen Is Mightier Than the Keyboard: Advantages of longhand over laptop note taking. Psychological Science, 25(6), 1159-1168. https://doi.org/10.1177/0956797614524581.

Seemiller, C., \& Grace, M. (2016). Generation Z Goes to College. New York, NY: Jossey-Bass.

\section{Copyright Disclaimer}

Copyright reserved by the author(s).

This article is an open-access article distributed under the terms and conditions of the Creative Commons Attribution license (http://creativecommons.org/licenses/by/3.0/). 